\title{
PREDIKSI TINGKAT BAHAYA EROSI MENGGUNAKAN SISTEM INFORMASI GEOGRAFIS (SIG) DI DAERAH TANGKAPAN AIR DANAU WISATA BANDAR KAYANGAN
}

\author{
Eva Suyanti ${ }^{1}$, Hadinoto ${ }^{2}$ dan Muhammad Ikhwan ${ }^{2}$ \\ ${ }^{1}$ Mahasiswa Fakultas Kehutanan Universitas Lancang Kuning \\ ${ }^{2}$ Staf Pengajar Fakultas Kehutanan Universitas Lancang Kuning \\ JIn. Yos Sudarso Km. 8 Rumbai Pekanbaru Riau \\ Email : evasuyanti83@yahoo.co.id, hdinto@yahoo.co.id, dan mmighwan@yahoo.com
}

\begin{abstract}
This study aims to determine the level of erosion hazard through erosion prediction by USLE method and Geographic Information System (GIS) at Water Catchment Area (WCA) Danau Wisata Bandar Kayangan. This research was conducted at WCA Danau Wisata Bandar Kayangan, Limbungan Village, District Rumbai, Pekanbaru. The research data was collected by survey method. Secondary data collection includes a slope digital map, land cover map, rainfall data, and soil type map of WCA Danau Wisata Bandar Kayangan. While the primary data is done by field checking to know land use pattern and soil type around WCA Danau Wisata Bandar Kayangan. The result shows that the erosivity index $(R)$ is 108 . The soil erodibility index $(K)$ in Podsolik Merah Kuning (PMK) is 0.166. Slope length index (LS) on slope $<8 \%$ flatland (20), 8 - 15\% ramps (15), 16 - 25\% slightly steep (10). Crop management and soil conservation (CP) index covers settlement (1), Bush / 0.01), plantation $(0,02)$, and lake $(0,01)$. The result of overlay of rainfall maps, soil type, slope class, and crop management and soil conservation obtained 46 land units at WCA Danau Wisata Bandar Kayangan. The highest Erosion Hazard Index (EHI) is found on land unit 45 of 358 on residential land cover. The largest potential erosion on land unit 44 with soil loss is 41,189.45 ton / ha / yr. Level of EHI in WCA Area of Danau Wisata Bandar Kayangan includes Class EHI 1: Very Light area of 32,627 ha; EHI Class 2: Lightweight of 59.86 ha; Class EHI 3: Medium area of 247.52 ha; Class EHI 4: Weight of 977,127 ha, Class EHI 5: Very Weight of 4,549.43 ha.

Keywords: Erosion, Erosion Hazard Level, Water Catchment Area
\end{abstract}

\section{PENDAHULUAN}

Erosi merupakan suatu fenomena alam, dimana terjadi pengikisan di bagian permukaan tanah bagian atas oleh pergerakan air ataupun angin. Besarnya erosi sangat tergantung dari faktor-faktor alam ditempat terjadinya erosi tersebut, akan tetapi saat ini manusia juga berperan penting atas terjadinya erosi. Adapun faktor-faktor alam yang mempengaruhi erosi adalah erodibilitas tanah, karakteristik landskap dan iklim. Akibat dari adanya pengaruh manusia dalam proses peningkatan laju erosi seperti pemanfaatan lahan yang tidak sesuai dengan peruntukkannya atau pengelolaan lahan yang tidak didasari tindakan konservasi tanah dan 
air menyebakan perlunya dilakukan suatu prediksi laju erosi tanah.

Prediksi erosi nantinya dapat dilihat berdasarkan pemetaan yang dilakukan menggunakan Sistem Informasi Geografis (SIG) yang merupakan teknologi berbasis spasial yang sangat populer saat ini. Prediksi erosi dengan metode USLE juga bisa menggunakan SIG dalam perhitungannya. Selain itu SIG dapat memanejemen data yang bereferensi geografi dengan cepat sehingga membuat studi tentang erosi bisa lebih mudah, khususnya bila harus mengulang menganalisis data-data pada daerah yang sama (Amorea et al., 2004 dalam Abdul, R. 2008). Mengetahui besarnya erosi yang terjadi di suatu wilayah merupakan hal yang penting karena selain dapat mengetahui banyaknya tanah yang terangkut juga dapat digunakan sebagai salah satu jalan untuk mencari sebuah solusi dari permasalahan tersebut. Oleh karena itu, untuk mengetahui besarnya erosi yang terjadi perlu dilakukan penelitian tentang "Prediksi Tingkat Bahaya Erosi Menggunakan Sistem Informasi Geografis (SIG) di Daerah Tangkapan Air Danau Wisata Bandar Kayangan"

\section{Tujuan}

Tujuan penelitian ini adalah mengidentifikasi tingkat bahaya erosi melalui prediksi erosi dengan metode USLE dan Sistem Informasi Geografis (SIG).

\section{METODE PENELITIAN}

\section{Tempat dan Waktu}

Penelitian ini dilakukan di DTA Danau Wisata Bandar Kayangan Kelurahan Limbungan, Kecamatan Rumbai, Pekanbaru. Penelitian ini dilaksanakan selama 2 bulan, yaitu pada bulan November-Desember 2016.

\section{Alat dan Bahan}

Adapun alat yang digunakan dalam penelitian ini adalah perangkat SIG antara lain: hardware yaitukomputer dan softwarenya Arcgis 10.3, kamera digital, GPS, dan alat tulis. Sedangkan bahan yang digunakan dalam penelitian ini adalah peta digital kelerengan DTA Danau Wisata Bandar Kayangan tahun 2014, peta tutupan lahan DTA Danau Wisata Bandar Kayangan tahun 2014, data curah hujan DTA Danau Wisata Bandar Kayangan tahun 2015, dan peta jenis tanah DTA Danau Wisata Bandar Kayangan tahun 2016. 


\section{Pengumpulan Data}

Penelitian ini menggunakan metode survei. Metode survei adalah metode yang bertujuan untuk mengumpulkan data dari lembaga. Data yang di kumpulkan terdiri dari data primer dan data sekunder. Pengambilan data primer dilakukan pada saat cek lapangan. Adapun pengambilan data primer untuk mengetahui tutupan lahan ataupun pola penggunaan lahan dan jenis tanah yang dilakukan di sekitar di DTA Danau Wisata Bandar Kayangan. Sedangkan data sekunder meliputi Data curah hujan tahun 2015, Peta digital jenis tanah tahun 2014, Peta digital tutupan lahan tahun 2014, Peta digital kelerangan tahun 2014.

\section{Pengolahan Data}

Data-data yang digunakan berasal dari peta digital DAS Siak. Informasi yang terdapat dalam peta das atau kemampuan tanah bermacammacam, untuk memilih sebuah informasi data yang diinginkan harus dilakukan dengan proses seleksi, tujuannya adalah untuk mendapatkan informasi data yang diinginkan seperti; informasi penggunaan lahan, kemiringan lereng, dan tekstur tanah.

\section{Analisis Data}

Metode analisis data yang digunakan untuk mencapai tujuan penelitian adalah metode analisis kuantitatif dengan menggunakan metode pendekatan analisis tumpang susun/overlay parameter-parameter erosi berjenjang tertimbang dengan menggunakan Sistem Informasi georgrafis (SIG). Overlay dilakukan dengan input empat peta tematik, yaitu: peta curah hujan, peta jenis tanah, peta kelerengan dan peta tutupan lahan dimana kelima peta tersebut merupakan parameterparameter kerentanan erosi dalam penelitian ini.

Overlay dilakukan tidak hanya melibatkan unsur spasial dari masingmasing parameter kerentanan erosi saja tapi tidak kalah pentingnya adalah overlay atribut yang menyertainya. Metode aritmatika yang digunakan dalam proses overlay dapat berupa penambahan, pengkalian dan perpangkatan. Untuk pembuatan peta tingkat bahaya erosi metode aritmatika yang digunakan pada proses overlay dari parameter-parameter tingkat bahaya erosi berupa metode pengkalian antara harkat dengan bobot pada masing-masing parameter kerentanan tingkat bahaya erosi. Pembuatan nilai 
interval kelas tingkat bahaya erosi bertujuan untuk membedakan kelas tingkat bahaya antara yang satu dengan yang lain.

Rumus yang digunakan untuk membuat kelas interval modifikasi dari rumus USLE yaitu:

\section{$A=R \times K \times L S \times C P$}

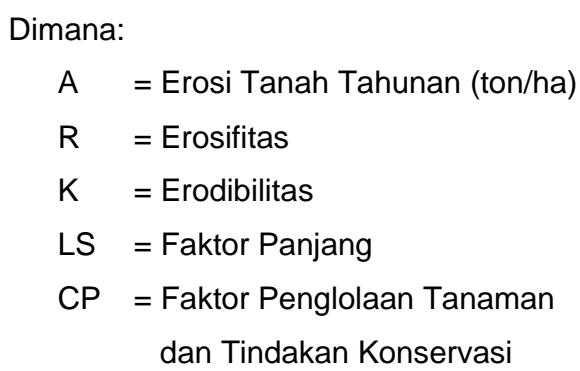

Tabel 1. Klasifikasi Tingkat Bahaya Erosi (The clasification of erosion danger level)

\begin{tabular}{|c|c|c|c|}
\hline No & $\begin{array}{l}\text { Relas BBE (Class of } \\
\text { gosion denger ked) }\end{array}$ & 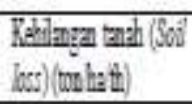 & Ketragna (Remati) \\
\hline 1 & I & 15 & Sapptrugen (Tor light \\
\hline 2 & $\mathbb{I}$ & $16-60$ & Pman (Iigh) \\
\hline 3 & II & $60-180$ & Sedang (labirace) \\
\hline 4 & IN & $180-480$ & Bert (Bany) \\
\hline 5 & V & 2480 & Sapotbert (Fo hav) \\
\hline
\end{tabular}

KONDISI UMUM LOKASI PENELITIAN DTA Danau Wisata Bandar Kayangan

DTA Danau Wisata Bandar Kayangan yang terletak di Kelurahan Limbungan, Kecamatan Rumbai, Pekanbaru dan merupakan salah satu Hutan Kota Pekanbaru yang terletak antara $00^{\circ} 34^{\prime} 43,00^{\prime \prime}$ - 00036'00,00" LU dan $101^{0} 37^{\prime} 35,00 "-101^{0} 28,58,00$ BT.
Dengan luas luas genangan air sekitar 82,263 ha.

Terdapat dua sungai yang mengaliri Danau Wisata Bandar Kayangan yaitu Sungai Limbungan dan Sungai Pengambang yang merupakan kedua anak Sungai Siak yang mengalir dari barat ke timur. DTA Danau Wisata Bandar Kayangan umumnya beriklim tropis dengan suhu udara maksimum berkisar antara $34^{\circ} \mathrm{C}-35^{\circ} \mathrm{C}$ dan suhu minimum antara $20^{\circ} \mathrm{C}-23^{\circ} \mathrm{C}$.

Curah hujan 1.786,8 mm/thn. Sebelum berganti nama menjadi Danau Wisata Bandar Kayangan pada tahun 2011, areal ini disebut Danau Buatan yang dikenal dengan Desa Lembah Sari.

\section{Batas Penelitian}

Adapun batas penelitian ini dilakukan dengan menentukan daerah yang termasuk pada Catchmen Area yang dilihat pada peta kontur pada dan dilakukan pemotongan batas wilayah penelitian.

\section{HASIL DAN PEMBAHASAN}

\section{Indeks Erosivitas (R)}

Diperoleh jumlah curah hujan di DTA Danau Wisata Bandar Kayangan yaitu 1.786,8 $\mathrm{mm} / \mathrm{thn}$ dimana berdasarkan indeks erosivitas dalam Utomo (1989) diperoleh indeks $R$ 
sebesar 108 dengan luas 5.975,913 ha. Tinggi rendahnya intensitas hujan akan mencerminkan besar kecilnya energi kinetik yang dihasilkan yang dapat menentukan besar kecilnya erosi yang akan diakibatkannya. Dengan demikian semakin banyak pula partikel tanah yang terlepas yang kemudian terlempar bersama percikan air. Pengaruh energi air hujan ini dapat dikurangi atau dihilangkan dengan penutupan tanah serapat mungkin.

\section{Nilai Indeks Erodibilitas (K)}

Berdasarkan peta jenis tanah diketahui bahwa jenis tanah di DTA Danau Wisata Bandar Kayangan adalah Podsolik Merah Kuning (PMK) dengan indeks $\mathrm{K}$ 0,166. Nilai $\mathrm{K}$ merupakan suatu nilai yang menunjukkan kepekaan suatu jenis tanah. Semakin besar nilai $\mathrm{K}$ maka tanah semakin mudah tererosi, sebaliknya semakin kecil nilai $\mathrm{K}$ maka tanah semakin tahan terhadap erosi. Adapun tingkat kepekaan atau ketahanan tanah terhadap erosi dapat diubah atau diusahakan menjadi lebih mantap atau stabil yaitu dengan cara merubah faktor-faktor yang berpengaruh terhadap tinggi rendahnya nilai $\mathrm{K}$. Hudson (1978) menyatakan bahwa selain sifat fisik tanah, faktor pengelolaan terhadap tanah sangat berpengaruh terhadap tingkat erodibilitas suatu tanah.

Erodibilitas tanah dipengaruhi oleh tekstur, struktur, permeabilitas dan kandungan bahan organik tanah. Berdasarkan peta jenis tanah diketahui bahwa jenis tanah di DTA Danau Wisata Bandar Kayangan di dominasi oleh jenis tanah Podsolik Merah Kuning (PMK) dengan nilai $K$ yaitu 0,166 pada luasan 5.893,6. Tanah PMK mempunyai sifat peka terhadap erosi, perkolasi dan infiltrasi yang rendah, ph Tanah yang rendah (4-5), kandungan Al yang tinggi, kandungan bahan organik yang rendah, serta ketersedian unsur hara bagi tanaman rendah (Harjoso, 2002). Bahan organik sangat berperan pada proses pembentukan dan pengikatan, serta penstabilan agregat tanah. Pengaruh utama bahan organik adalah memperlambat aliran permukaan, meningkatkan infiltrasi, dan memantapkan agregat tanah. Hal ini sesuai dengan pendapat Asdak (2002) bahwa unsur organik cenderung memperbaiki struktur tanah dan bersifat meningkatkan permeabilitas tanah, kapasitas tampung air tanah, dan kesuburan tanah. 
Indeks Panjang dan Kemiringan (LS)

Berdasarkan kelas lereng keadaan topografi pada DTA Danau Wisata Bandar Kayangan yaitu agak curam dengan kelerengan $16-25 \%$, landai dengan kelerengan 8 - $15 \%$, dan $<8 \%$ yaitu datar. Menurut Andrian, Supriadi dan Marpuang (2014), bahwa semakin panjang lereng pada tanah akan semakin besar pula kecepatan aliran air di permukaannya sehingga pengikisan terhadap bagian-bagian tanah semakin besar. Semakin panjang lereng suatu lahan menyebabkan semakin banyak air permukaan yang terakumulasi, sehingga aliran permukaan menjadi lebih tinggi kecepatannya.

Indeks Pengelolaan Tanaman dan Konservasi Tanah (CP)

Dari peta penutupan dan pengelolaan lahan pada gambar 14 dapat diketahui pola penggunaan lahan yang lebih didominasi oleh tipe semak/belukar. Nilai C pada penggunaan lahan pemukiman yaitu 1 , semak/belukar 0,01, perkebunan 0,02, dan Danau 0,01. Keadaan vegetasi (penutup tanah) mempengaruhi tingkat erosi yang terjadi, dimana pada tanahtanah yang berlereng dan terbuka, memiliki bahaya erosi yang lebih besar dibandingkan dengan tanah yang bervegatasi lebat. Hal ini dikarenakan pada tanah yang tidak memiliki tutupan lahan, butiran hujan yang turun akan langsung mengenai permukaan tanah. Sedangkan, tanah yang memiliki vegetasi dapat menahan butiran-butiran hujan yang turun serta menahan tanah yang terkena butiran-butiran hujan untuk terbawa air hujan menggunakan akar tanaman.

\section{Land Unit DTA Danau Wisata Bandar Kayangan}

Hasil Overlay peta curah hujan, jenis tanah, kelas lereng, dan pengelolaan tanaman dan konservasi tanah yang kemudian diperoleh peta land unit DTA Danau Wisata Bandar Kayangan pada gambar 1 .

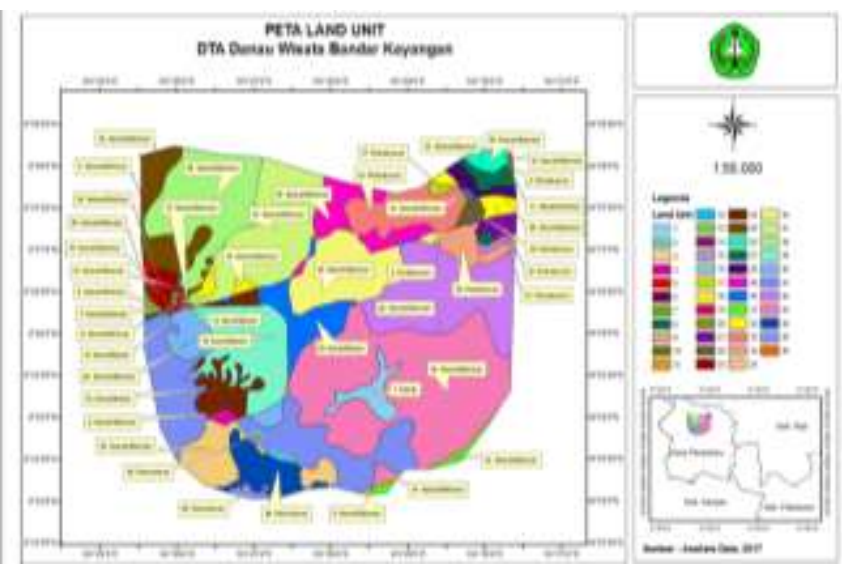

Gambar 1. Peta Land Unit DTA Danau Wisata Bandar Kayangan 


\section{Tingkat Bahaya Erosi}

Tingkat Bahaya Erosi adalah prakiraan jumlah tanah yang hilang maksimum yang akan terjadi pada suatu lahan, bila pengelolaan tanaman dan tindakan konservasi tanah tidak mengalami perubahan. Tingkat bahaya erosi terdiri dari Indeks bahaya erosi, erosi potensial, dan kelas tingkat bahaya erosi. Indeks bahaya erosi tertinggi yaitu pada land unit 45 dengan indeks bahaya erosi 358 pada gambar 2 dengan tutupan lahan pemukiman. Adanya perbedaan indeks bahaya erosi ini dikarenakan faktor pengkali indeks yang berbeda yaitu $R, C P, L S, K$.

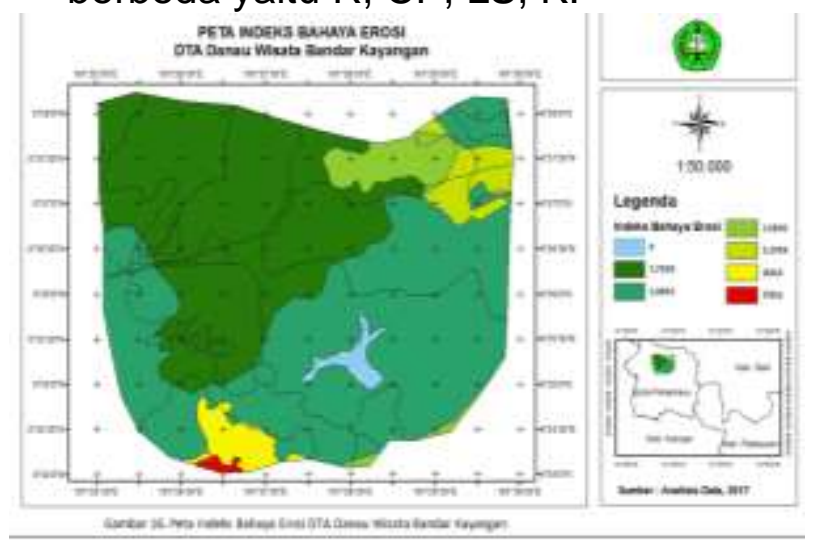

Gambar 2. Peta Indeks Bahaya Erosi DTA Danau Wisata Bandar Kayangan.

\section{Erosi Potensial}

Erosi potensial merupakan energi yang dihitung dengan penjumlahan USLE tanpa memperhitungkan faktor Vegetasi dan tindakan konservasi tanah.

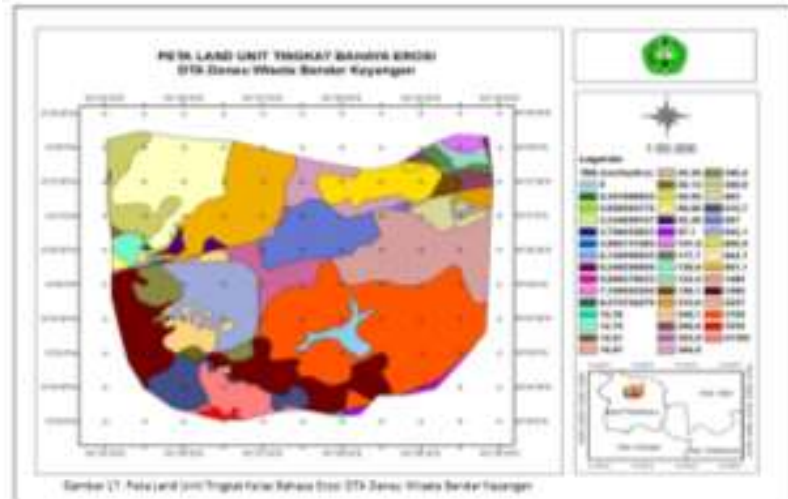

Gambar 3. Peta Land Unit Tingkat Bahaya Erosi DTA Danau Wisata Bandar Kayangan

Besarnya kehilangan tanah (Soil Lost Equation) per land unit dapat dilihat pada gambar 3. Potensi erosi terbesar terjadi pada land unit 44 dengan kehilangan tanah berkisar 34.240 ton/ha/thn. Faktor penyebab utama terjadinya erosi pada land unit 44 adalah karena pemberian nilai $C$ yang tinggi $(1,000)$ akibat dari pola penggunan lahan pemukiman dengan luas 153,166 ha. Sedangkan potensi erosi dengan kehilangan tanah terkecil yaitu 0,1635 ton/ha/thn pada land unit 15 dengan luasan semak belukar berkisar 0,202 ha dengan tutupan lahan semak/belukar. Besarnya potensi erosi yang terjadi didominasi di daerah dengan tutupan lahan Semak/belukar dan pemukiman. Selain itu, luas lahan yang berbedabeda setelah di overlay juga mempengaruhi besarnya erosi yang terjadi pada 46 land unit di atas.. 
Tabel 2. Kelas Tingkat Bahaya Erosi DTA Danau Wisata Bandar Kayangan

\begin{tabular}{|c|c|c|c|c|c|c|}
\hline No & $\frac{\mathrm{L}}{(\mathrm{Ha}}$ & $\begin{array}{c}\text { Perserasi } \\
\text { (\%/a) }\end{array}$ & $\begin{array}{c}\text { BEE } \\
\text { (twhath) }\end{array}$ & $\begin{array}{c}\text { Rehilmgan } \\
\text { mah (Soil } \\
\text { loxs) } \\
\text { (torhatun) }\end{array}$ & $\begin{array}{c}\text { Relas } \\
\text { BE(Cias of } \\
\text { evocion } \\
\text { denger lever) }\end{array}$ & Reterangan \\
\hline 1 & 3263 & I & $847+59$ & $<15$ & 1 & Sancet Rugen \\
\hline 2 & 59.86 & $i$ & 162166 & 16.60 & II & Ringal \\
\hline 3 & 24752 & 4 & 811,114 & $60-180$ & III & Seting \\
\hline 4 & 977,12 & 17 & $2,437,4158$ & 184.40 & IV & Bert \\
\hline 5 & 4549 & 78 & 6098238 & 2480 & $\nabla$ & Smgat Berat \\
\hline
\end{tabular}

Erosi Sangat Berat dengan kehilangan tanah 47.928 ton/ha/thn dengan luasan 2.497,989 ha seperti pada tabel 2. Penurunan nilai erosi dan TBE pada lokasi penelitian perlu dilakukan terutama dengan kategori Berat dan Sangat Berat, hal ini diperlukan agar dimasa yang akan datang erosi yang terjadi tidak semakin besar terutama faktor pengelolaan tanaman dan tindakan konservasi tanah. Asdak (2002) mengatakan bahwa komponen yang dapat diubah untuk mencegah erosi adalah faktor pengelolaan tanaman $(C)$, pengelolaan tanah (P), dan faktor topografi (LS), sedangkan nilai erodibilitas (K) umumnya dianggap konstan kendati dapat berubah tergantung struktur tanah, tekstur tanah, bahan organik dan permeabilitas. Adapun sebaran peta kelas tingkat bahaya erosi dapat dilihat pada gambar 4 .

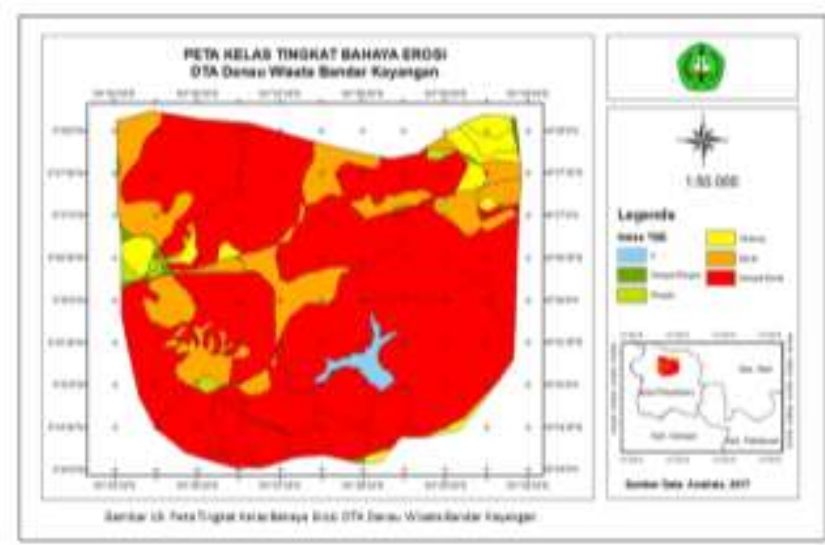

Gambar 4. Peta Kelas Tingkat Bahaya Erosi DTA Danau Wisata Bandar Kayangan

\section{KESIMPULAN DAN SARAN}

\section{Kesimpulan}

Tingkat Bahaya Erosi (TBE) di Wilayah DTA Danau Wisata Bandar Kayangan meliputi Kelas TBE 1: Sangat Ringan ( $<15$ ton/ha/thn) seluas 51,934 ha; Kelas TBE 2: Ringan (16-60 ton/ha/thn) seluas 75,336 ha; Kelas TBE 3: Sedang (60-180 ton/ha/thn) seluas 956,0003 ha; Kelas TBE 4: Berat (180480 ton/ha/thn) seluas 859,12 ha, Kelas TBE 5: Sangat Berat ( $>480$ ton/ha/thn) seluas 4946,9 ha.

\section{Saran}

Pada kawasan DTA Danau Wisata Bandar Kayangan yang teridentifikasi sebagai wilayah yang memiliki TBE Berat dan Sangat Berat perlu dilakukan upaya pencegahan erosi berupa tindakan konservasi tanah dan perbaikan pengolahan tanah. pada kawasan yang masih tergolong Sangat 
Ringan - Sedang juga perlu untuk tetap memperhatikan kegiatan pengolahan dan konservasi tanah, agar tingkat bahaya erosi tidak menjadi lebih berat.

\section{DAFTAR PUSTAKA}

Asdak, C. 2002. Hidrologi dan Pengelolaan Daerah Aliran Sungai. Yogyakarta : Gadjah Mada University Press.

Abdul, R. 2008. Prediksi Erosi Dengan Menggunakan Metode USLE Dan Sistem Informasi Geografis (SIG) Berbasis Piksel Di Daerah Tangkapan Air Danau Buyan. [Jurnal]. Denpasar. Pusat Penelitian Lingkungan Hidup. Universitas Udayana.

Andrian, Supriadi dan Purba Marpaung. 2014. Pengaruh Ketinggian Tempat dan Kemiringan Lereng Terhadap Produksi Karet (Hevea brasiliensis Muell. Arg.) di Kebun Hapesong PTPN III Tapanuli Selatan. Medan. Jurnal Online Agroekoteknologi . Vol.2 (3); 981 - 989.

Harjoso, T dan A. S. D. Purwantono. 2002. Pemanfaatan Tanah Podzolik Merah Kuning melalui Pemberian Pupuk Kandang dan EM4 bagi Program Pengembangan Baby Corn. Jurnal Pembangunan Pedesaan, 2(2): 27- 33.

Utomo, Wani Hadi.1994. Erosi dan Konservasi Tanah. IKIP. Malang.
Winarjo, S. 2005. Kesuburan Tanah Dasar Kesehatan dan Kualitas Tanah. Gava Media, Yogyakarta. 